\title{
CIPK9 is involved in seed oil regulation in Brassica napus L. and Arabidopsis thaliana (L.) Heynh.
}

Yanli Guo ${ }^{1,3}$, Yi Huang ${ }^{2}$, Jie Gao ${ }^{1}$, Yuanyuan Pu', Nan Wang ${ }^{1}$, Wenyun Shen², Jing Wen ${ }^{1}$, Bin Yi ${ }^{1}$, Chaozhi Ma', Jinxing $\mathrm{Tu}^{1}$, Tingdong $\mathrm{Fu}^{1}$, Jitao Zou ${ }^{2^{*}}$ and Jinxiong Shen ${ }^{1^{*}}$

\begin{abstract}
Background: Accumulation of storage compounds during seed development plays an important role in the life cycle of oilseed plants; these compounds provide carbon and energy resources to support the establishment of seedlings.

Results: In this study, we show that BnCIPK9 has a broad expression pattern in Brassica napus L. tissues and that wounding stress strongly induces its expression. The overexpression of BnCIPK9 during seed development reduced oil synthesis in transgenic B. napus compared to that observed in wild-type (WT) plants. Functional analysis revealed that seed oil content (OC) of complementation lines was similar to that of WT plants, whereas OC in Arabidopsis thaliana (L.) Heynh. Atcipk9 knockout mutants (cipk9) was higher than that of WT plants. Seedling of cipk9 mutants failed to establish roots on a sugar-free medium, but root establishment could be rescued by supplementation of sucrose or glucose. The phenotype of complementation transgenic lines was similar to that of WT plants when grown on sugarfree medium. Mutants, cipk9, cb/2, and cb/3 presented similar phenotypes, suggesting that CIPK9, CBL2, and CBL3 might work together and play similar roles in root establishment under sugar-free condition.

Conclusion: This study showed that BnCIPK9 and AtCIPK9 encode a protein kinase that is involved in sugar-related response and plays important roles in the regulation of energy reserves. Our results suggest that AtCIPK9 negatively regulates lipid accumulation and has a significant effect on early seedling establishment in $A$. thaliana. The functional characterization of CIPK9 provides insights into the regulation of OC, and might be used for improving OC in B. napus. We believe that our study makes a significant contribution to the literature because it provides information on how CIPKs coordinate stress regulation and energy signaling.
\end{abstract}

Keywords: Brassica napus L., Seed oil content, CIPK9, Sucrose, Seedling establishment, Arabidopsis thaliana

\section{Background}

Sucrose is transported from leaves to other tissues as a main product of photosynthesis, and it is also the main carbon and energy source for plants' reproduction and growth and for obtaining storage components such as oil, starch, and protein [1-4]. In oilseeds, lipids are the

\footnotetext{
*Correspondence: jitao.zou@nrc-cnrc.gc.ca; jxshen@mail.hzau.edu.cn

${ }^{1}$ National Key Laboratory of Crop Genetic Improvement/National

Engineering Research Center of Rapeseed, Huazhong Agricultural University, Wuhan 430070, China

${ }^{2}$ National Research Council Canada, Saskatoon, SK S7N0 W9, Canada

Full list of author information is available at the end of the article
}

major energy reserves and are stored in the form of triacylglycerols (TAGs) in oil bodies [5, 6]. Once germination begins, consumption of the energy reserves accumulated during seed maturation is necessary for energy production to ensure heterotrophic growth [7-10]. During the early postgermination stage, lipases initiate the hydrolysis of TAGs into glycerol and fatty acids (FAs), and the $\beta$-oxidation pathway depredates those FAs for carbon [11-16]. During seed germination, the young plant degrades energy reserves and transfers them into soluble molecules (e.g. sucrose), which can be transported throughout the plant. 
As a main carbon and energy source, sugars function as signaling molecules, represent the nutrient status of the plant, and regulate many nutrient-related genes [17-19]. In addition, sugars can regulate many biological processes, including starch synthesis, cell division, and growth. Conversely, sugar starvation can affect the plant's central development by enhancing photosynthetic activities and carbon remobilization [20, 21]. Sugar signaling can interact with several other signals including hormone, nitrogen [22], stress, and energy levels [2325]. However, there are few transcriptional factors (TFs) among the large number of genes regulated by sugars. A novel screening technology demonstrated the participation of several basic region-leucine zipper (bZIP) and $\mathrm{v}$-myb avain myeloblastosis viral oncogene homolog (MYB) TFs in the sugar signaling system [18, 26-29]. The cis-acting elements found among the target genes provide clues for identifying trans-acting factors in sugar response. For instance, the protein kinase SnRK1A has been identified as a sugar response transcriptional factor (TF) in rice, based on the cis-acting elements present in the promoter of gene $\alpha$-amylase $3(\alpha-A m y 3)$ [30]. Acting both as a structural component and as an energy source, sugar is an important substrate for plants during their active growth, seed production, and response to stress.

Energy-signaling protein kinases are conserved among the different species of eukaryotes: SNF1 in yeast, AMPactivated protein kinase (AMPK) in mammals [31-35], and SnRK1 [36-40], and SnRK2.6 in plants [41]. The Snf1-related protein kinases (SnRKs) found in plants comprise families SnRK1, SnRK2, and SnRK3, which include three, 10, and 25 members, respectively [40, 42]. Given their ability to interact with calcineurin B-like proteins (CBLs) [43-50], members of the SnRK3 family are also named CBL-interacting protein kinases (CIPKs). However, their roles in energy signaling and stress response remain unknown. To unravel the roles of the CIPKs in the regulation of carbohydrate and energy metabolism, we aimed to identify the kinases involved in seed oil production. In oilseed plants, such as rapeseed, a large proportion of photoassimilate is transported to seeds for TAG synthesis, which demands abundant energy and carbon sources. The carbon level relative to that of nitrogen is then used as a signal to accelerate or decelerate the rate of oil synthesis [51, 52]. Overall, the analyses performed in these previous studies suggested that sugar and energy supplies in source tissues of oilseed plants affect seed oil synthesis.

Our reverse genetic study suggested that $B n C I P K 9$ is a negative regulator of seed oil synthesis in $B$. napus. To further elucidate its function, we overexpressed $B n C I P K 9$ in B. napus, and demonstrated its roles in reducing $\mathrm{OC}$. In the present study, we also investigated the function of
Arabidopsis thaliana (L.) Heynh. AtCIPK9 in lipid accumulation and its role in root establishment.

\section{Results \\ Phenotypic variation}

Seeds from the parental lines, P1 (high-oil parent) and P2 (low-oil parent), showed a statistically significant difference in their seed oil content (OC): 46.4\% $( \pm 0.7 ; n=4)$ and $41.1 \%( \pm 0.9 ; n=2)$, respectively (Fig. 1a). The OC exhibited transgressive segregation, with a minimum of $30.3 \%( \pm 0.8)$ and a maximum of $51.8 \%( \pm 0.7)$ in the $F_{2}$ populations of P1/P2 (Fig. 1a). Within these populations, the seven lines with the highest OC were H4 (51.8\%), H12 (50.5\%), H133 (50.1\%), H41 (49.9\%), H154 (49.1\%), H86 (49.0\%), and H64 (48.9\%), and the seven lines with the lowest OC were L307 (33.2\%), L161 (32.3\%), L89 (31.8\%), L179 (31.5\%), L267 (31.4\%), L306 (30.7\%), and L270 (30.3\%).

Microarray analysis conducted using the above-mentioned rapeseed lines allowed identifying 10 genes potentially involved in OC regulation, including $B n C I P K 9$. Gene expression analysis showed that $B n C I P K 9$ was differentially expressed between the high- and the low-oil content lines from $\mathrm{F}_{2}$ populations, with higher expression in the low-oil lines than in the high-oil content lines (Fig. 1b). The results of quantitative real-time PCR (qRTPCR) analysis further confirmed a negative correlation between the expression level of $B n C I P K 9$ and the $\mathrm{OC}$ of rapeseed seeds (Fig. 1c).

The YISNF1 is known to negatively regulate lipid accumulation in yeast [53]. Consistent with this finding, our results suggested that $B n C I P K 9$ was a negative regulator of $\mathrm{OC}$ in rapeseed. Therefore, we further attempted to characterize the molecular mechanism underlying this regulation. Full-length $B n C I P K 9$ sequences, including the $5^{\prime}$-untranslated region (5'-UTR) were obtained from rapeseed lines. Analysis of rapeseed genome suggested that $B n C I P K 9$ has four copies, and that is conserved (data not shown). Annotation of the 3050-bp (BnCIPK9 promoter1) and a 3372-bp (BnCIPK9 promoter2) fragments isolated from the $5^{\prime}$-UTR next to the BnCIPK9 genomic locus from the parental line $\mathrm{P} 1$ revealed several cis-elements in this region. The main difference between $B n C I P K 9$ promoter 1 and promoter 2 sequences was the presence of a $264 \mathrm{bp}$ insertion/deletion at the position -281 in BnCIPK9 promoter2 (Fig. 4a).

\section{Expression analysis of BnCIPK9}

The A. thaliana homolog of BnCIPK9, AtCIPK9, is expressed in several tissues, including leaves, stem, flowers, and siliques [54-56]. At 24 days after pollination (DAP), high BnCIPK9 transcription levels were observed in the stem, leaves, and in silique walls, whereas low 


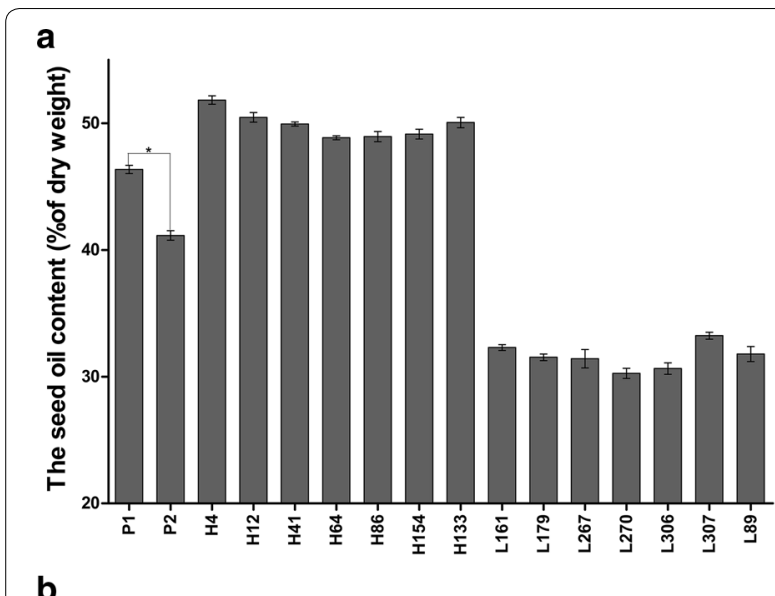

b

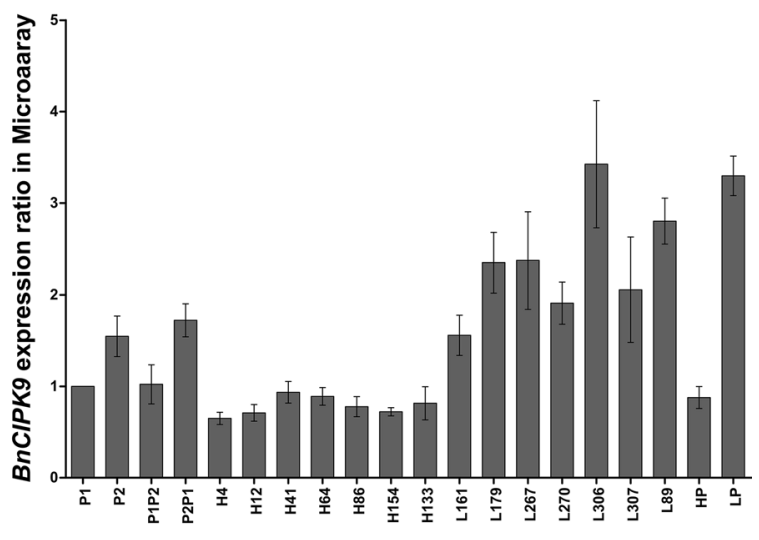

C

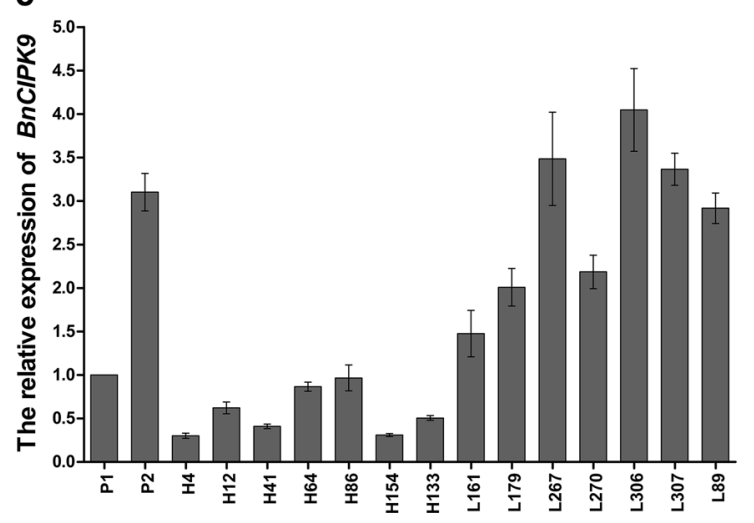

Fig. 1 Negative regulation of BnCIPK9 according to seed oil content in Brassica napus. a Seed oil contents of various rapeseed lines expressed as a percentage of dry weight. For P1 and P2, Bars represent mean values of seed oil content, and error bars indicate its standard deviation (SD) $(n=2-4)$; the asterisk indicates a significant difference $(P<0.05)$ in seed oil contents between P1 and P2. b Different expression levels of BnCIPK9 in the high-oil and low-oil content lines, as determined by microarray analysis. Error bars indicate SD $(n=6)$. c Relative expression analysis of BnCIPK9 in the rapeseed lines examined. The data are mean \pm SD of three replicates transcription levels were found in flowers, buds, 24 DAP seeds, and especially in the roots (Fig. 2a). A qRT-PCT was performed to characterize the relative accumulation of mRNA transcripts of $B n C I P K 9$ during the different developmental stages of P1 seeds, from 10 to 43 DAP (Fig. 2b). Transcript levels were relatively low during early seed development (up to 15 DAP), but a sharp increase was observed from 15 to 20 DAP, after which transcript levels gradually decreased from 25 to 43 DAP (Fig. 2b). These results indicated that the expression pattern of BnCIPK9 is similar to that of AtCIPK9; both are expressed in various organs, including photosynthetic and non-photosynthetic tissues.

The expression profiles of $B n C I P K 9$ were also evaluated based on $\beta$-glucuronidase (GUS) activity in transgenic $A$. thaliana seedlings carrying GUS, under the control of $B n C I P K 9$ promoters 1 and 2 (BnCIPK9 promotor1:GUS, and $B n C I P K 9$ promotor2:GUS). This analysis revealed a similar expression pattern between plants transformed with BnCIPK9 promotor1:GUS (Fig. 2c) and BnCIPK9 promotor2:GUS (data not shown). Wounding stress signal strongly induced the expression of BnCIPK9 (Fig. 2c2, c3, c5). Although BnCIPK9 was expressed in siliques, GUS activity was mainly restricted to the stigma and receptacle of developing siliques (Fig. 2c1, c2). In the inflorescence, substantial GUS activity was predominantly detected in the anthers and stamen filaments and in the vasculature of mature petals and sepals (Fig. 2c1, c3). In addition, BnCIPK9 was expressed in all tissues of 7-day-old seedlings, particularly in vascular tissue of leaves (Fig. 2c4). In adult plants, low GUS activity was detected in the typical rosette leaf and old stems (Fig. 2c5, c6). Overall, GUS activity profiles were generally consistent with the mRNA profiles obtained using qRT-PCR.

\section{Decrease in lipid storage in the seeds of transgenic plants overexpressing BnCIPK9}

We generated transgenic rapeseed plants overexpressing $B n C I P K 9$ to determine whether an increase in BnCIPK9 expression would reduce the $\mathrm{OC}$ in seeds. To specifically control for the accumulation of lipids in mature seeds, the $B n C I P K 9$ transgene was expressed under the control of seed-specific BnNapin promoter. We recovered four independent lines the pattern and rate of growth, leaf number, and leaf size of which were all normal. The T3 mature seeds from the transgenic plants were normal in size (Fig. 3a, d), and transgenic plants had high levels of BnCIPK9 expression (Fig. 3b). Seeds harvested from four fully mature transgenic plants were used for further studies. The transgenic plants with the increased levels of endogenous BnCIPK9 expression had a significantly lower OC than the non-transgenic plants (Fig. 3c). 

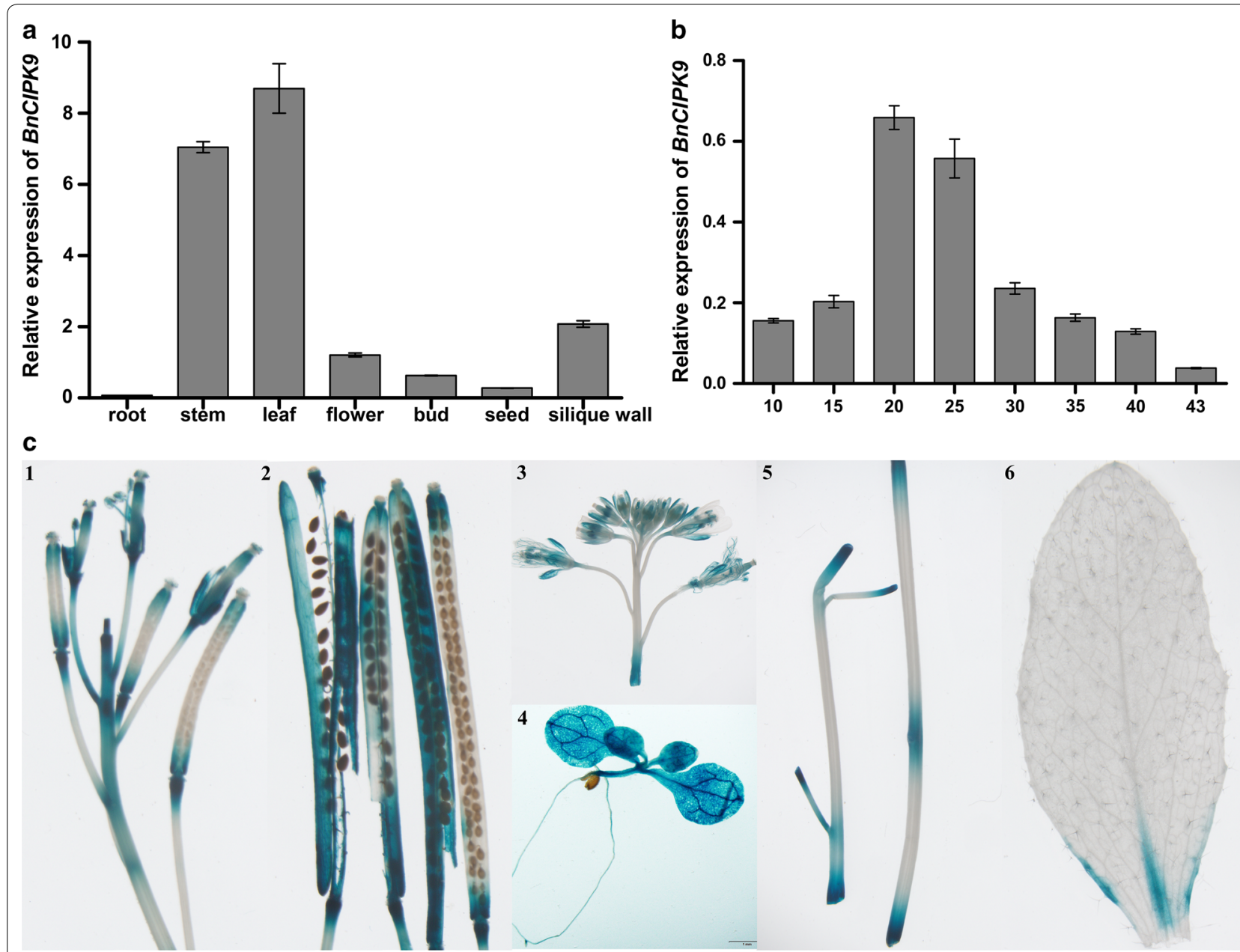

6

Fig. 2 Expression patterns of BnCIPK9 in the high-oil content parent (P1). a Spatial and temporal expression analyses of BnCIPK9 in roots, stem, leaves, 24 days after pollination (DAP) seeds, 24DAP slique wall, buds, and flowers using quantitative real-time PCR (qRT-PCR). Total RNA was isolated from the different tissues (roots, stem, leaves, 24DAP seeds, 24DAP silique wall, buds, and flowers); qRT-PCR was performed with BnCIPK9-specific primers and BnaUBC9-specific primers. Gene BnaUBC9 was used as an internal control for normalization. The data shown are mean \pm standard deviation (SD) of three technical replicates. b BnCIPK9 expression profile using qRT-PCR at different seed-development stages (10, 10DAP; 15, 15DAP; 20, 20DAP; 25, 25DAP; 30, 30DAP; 35, 35DAP; 40, 40DAP; 43, 43DAP). Tissues were collected at different seed-development stages, and RNA was isolated to obtain first-strand CDNA. The qRT-PCR was performed with BnCIPK9-specific and BnaUBC9-specific primers. BnaUBC9 expression levels were used as an internal control. The data shown are mean \pm SD of three technical replicates. c GUS staining of different tissues in BnCIPK9:GUS transgenic plants. Gus activity in 7-day-old seedlings (4) and individual organs of adult plant $(1-3,5,6)$, siliques $(1,2)$, whole inflorescence (3), stem (5), mature leaf (6). Scale $=2 \mathrm{~mm}$ (siliques, whole inflorescence, stem, mature leaf), $1 \mathrm{~mm}$ in 7-day-old seedlings

\section{Characterization of promoters 1 and 2 of BnCIPK9}

To determine the regulatory elements of $B n C I P K 9$, the promoter regions $(3.0 \mathrm{~kb}$ fragment upstream of the translation start site) were isolated from the rapeseed genomic DNA. We performed an in silico analysis of $B n C I P K 9$ promoter1 (3050 bp) and BnCIPK9 promoter2 (3372 bp) fragments to find the cis-elements related with sugar response. The analysis of the promoter fragments was performed using the PLACE database (http://www. dna.affrc.go.jp/PLACE), searching for the motifs that might be involved in gene suppression by sugars (Fig. 4a).
Seventeen and 23 potential sugar response motifs were characterized from $B n C I P K 9$ promoter1 and promoter2, respectively. One of the most interesting elements found in the promoters was the TATCCA motif, which has also been found in the $5^{\prime}$-UTR of $\alpha$-Amy3D from rice and characterized as a sugar response motif $[57,58]$. This motif occurs twice in promoter 1 (at -134 and -391 from ATG) and promoter2 (at -134 and -661 from ATG), separated by 252 and 516 bp, respectively. The I-box [59] was found four times within BnCIPK9 promoter1 and six times within $B n C I P K 9$ promoter2, but 


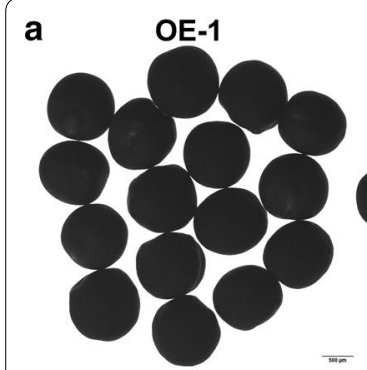

b

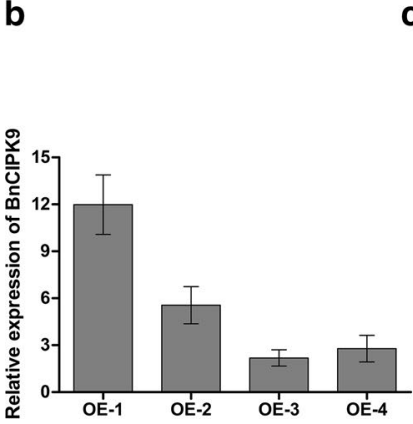

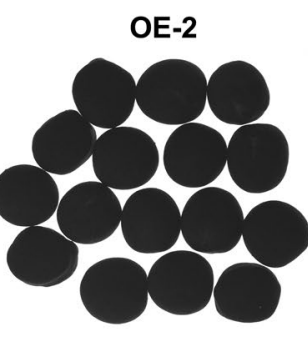

C
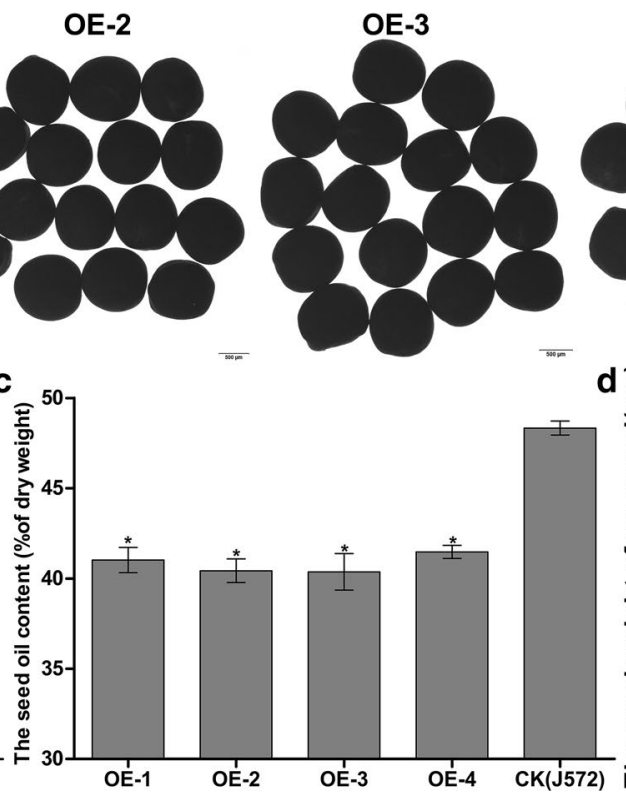
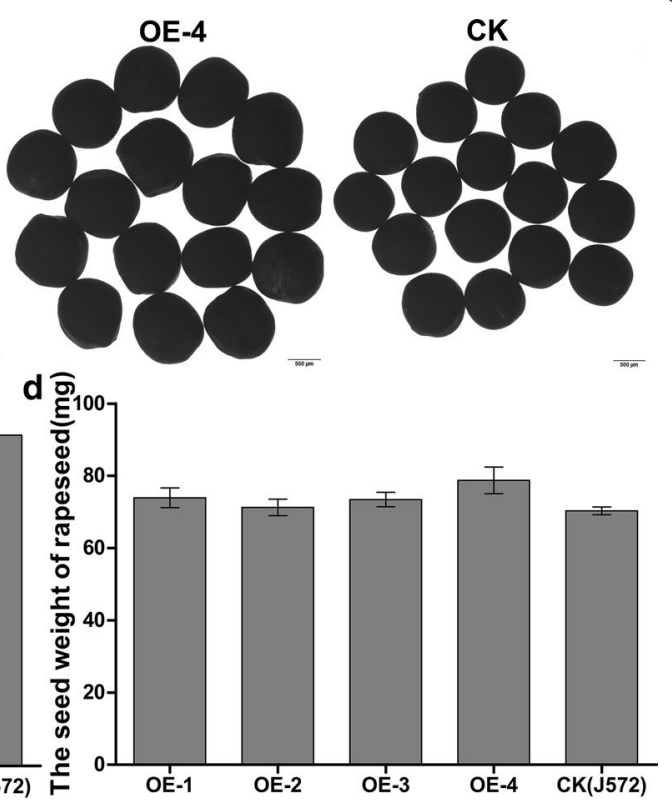

Fig. 3 Transgenic rapeseed plants overexpressing ProBnNapin:BnCIPK9T178D (BnCIPK9-OE) and analyses of seed oil content, seed size, and seed weight. a T3 generation of dried seeds of four independent ProBnNapin:BnCIPK9T178D overexpressing transgenic lines (OE-1, OE-2, OE-3, OE-4) and 572 (wild type, WT), used as the control. Bars correspond to $500 \mu \mathrm{m}$. b Expression levels of BnCIPK9 in the seeds of transgenic rapeseed lines as assessed by qRT-PCR. Bars represent mean \pm standard deviation (SD) (three technical replicates). c Total seed oil contents of transgenic rapeseed plants (T2), and 5572 (WT) used as the control. Bars indicate the SDs of different replicates. Asterisks indicate significant differences ( $P<0.05$ ) between transgenic and control (J572) plants. d Dry seed weight (15 seeds) of transgenic and J572 rapeseed plants. Error bars indicate the SD $(n \geq 5)$

only one I-box motif of $B n C I P K 9$ promoter2 overlapped with the MYBST1 element [60] (Fig. 4a). The MYBST1 element occurred four times within BnCIPK9 promoter1 and six times within BnCIPK9 promoter2. The E-box motifs [61, 62], which are likely seed-specific, occurred four times within $B n C I P K 9$ promoter1 and five times within BnCIPK9 promoter2.

To characterize the molecular mechanism of the regulation of BnCIPK9 by sugars, fragments of BnCIPK 9 promoter1 and $B n C I P K 9$ promoter2 upstream the ATG codon were used for GUS analysis. We examined the effects of sucrose and glucose (1 or $3 \% \mathrm{w} / \mathrm{v})$ supplementation in half-strength Murashige and Skoog (MS) medium on GUS expression. As a control, mannitol was used for imposing osmotic stress. Supplementation of $3 \%$ glucose significantly reduced GUS expression in promoter1:GUS lines compared to the medium without supplementation (Fig. 4b). Both $1 \%$ glucose and $1 \%$ mannitol resulted in lower GUS activity for the BnCIPK9 promoter2 in relation to the sugar-free condition (Fig. 4c). In the presence of both $3 \%$ sucrose and $3 \%$ glucose, a significant reduction in the GUS activity was observed in $B n C I P K 9$ promoter2:GUS transgenic lines, compared that observed on the medium without supplementation (Fig. 4c). Quantitative GUS assays suggested that the expression of BnCIPK9 promoter1 and BnCIPK9 promoter2 was reduced at different extents in the presence of sugar, and that these regions were particularly responsive to sucrose and glucose.

\section{Characterization of the promoter region of AtCIPK9}

The promoter region of AtCIPK9 contains two putative sugar-responsive elements, TATCCA and TAACAAA [63], which are found in gene $\alpha-A m y 3$. In addition, the promoter fragment includes an RY and an EVENINGAT motif $[64,65]$. Five I-box motifs were found in the promoter of AtCIPK9, but only one I-box motif overlapped the MYBST1A motif. The promoter of AtCIPK9 includes six E-box motifs, which potentially mediate gene expression in seeds. On half-strength MS supplemented with $1 \%$ sucrose, a reduction in the GUS activity was observed in AtCIPK9 promoter:GUS transgenic lines compared to that observed on the medium without sugar supplementation (Fig. 5b). On half-strength MS with $1 \%$ glucose, GUS expression in AtCIPK9 promoter:GUS transgenic lines was indistinguishable from that observed in the absence of sugar. In the presence of both $3 \%$ sucrose and 3\% glucose, GUS activities were reduced observed in the AtCIPK9 promoter:GUS transgenic lines 


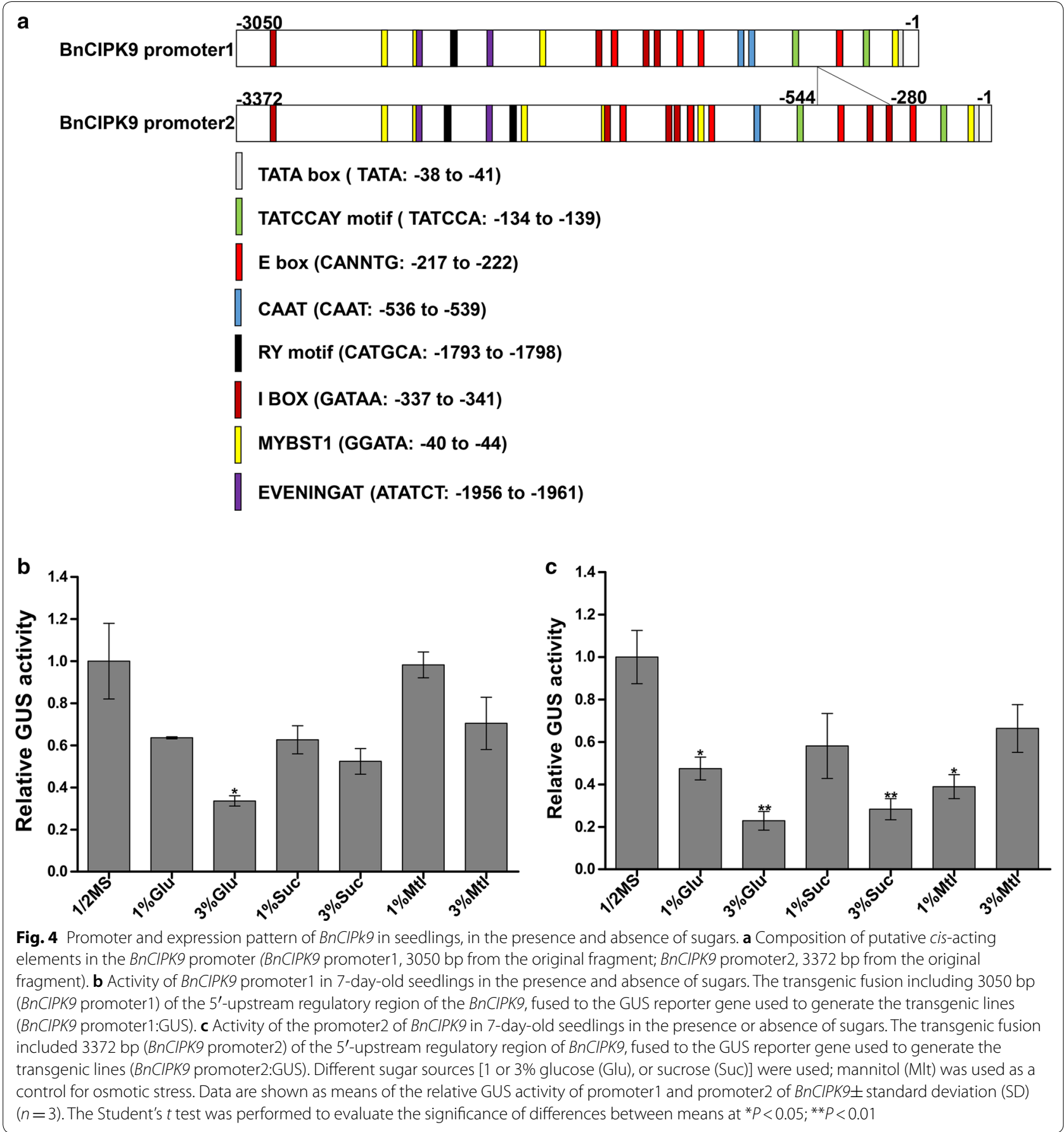

compared to that observed on the medium without sugar supplementation.

\section{Disruption of AtCIPK9 leads to an increase in TAG in seeds and in the failure establishment of root}

We obtained an A. thaliana mutant (Salk_058629) from the ABRC Stock Center containing a transfer-DNA insertion in the fourth exon (1115 bp from ATG) of the
AtCIPK9 (At1g01140) locus [54]. This mutant was designated cipk9. The transcript level of AtCIPK9 in cipk9 was 40-fold lower than that in wile-type (WT) plants during the early stage of silique development (6-10 DAP). Previous results from northern blot analysis also showed that the transcription of AtCIPK9 in this mutant line was disrupted [55]. The average OC in WT plants was $24.1 \%$, whereas in cipk 9 mutant plants it was $26.3 \%$ (Fig. 6a). 
a

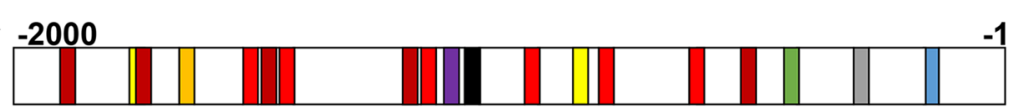

AtCIPK9 Promoter (2000bp)

TATA box (TATA:-283 to -286)

CAAT box (CAAT:-172 to -175$)$

TATCCAY motif (TATCCA:-385 to -390 )

E box ( CANNTG:-615 to $-620 ; 5)$

RY motif (CATGCA:-1011 to -1016)

AMYBOX1 (TAACAAA:-1545 to -1551)

EVENINGAT (ATATCT:-1045 to -1050)

MYBST1 (GGATA:-852 to $-857 ; 2$ )

I-BOX (GATAA:-496 to $-500 ; 5)$

b

1/2MS/-

Glucose
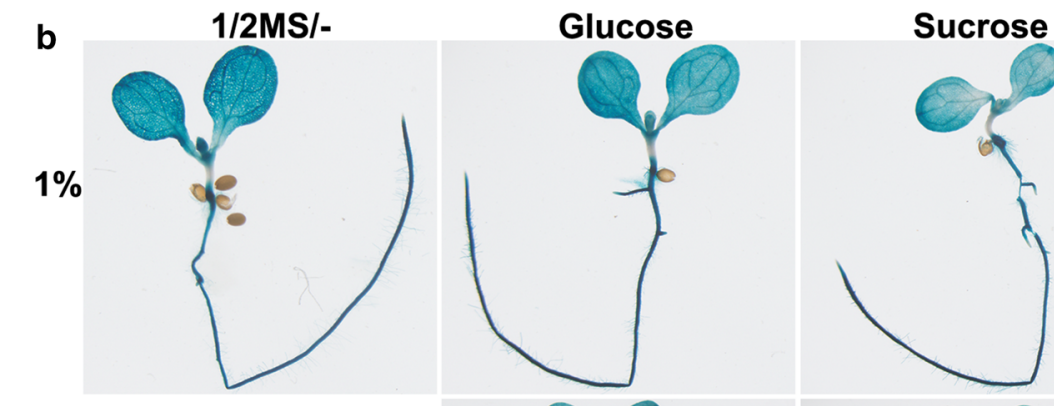

Mannitol

$3 \%$
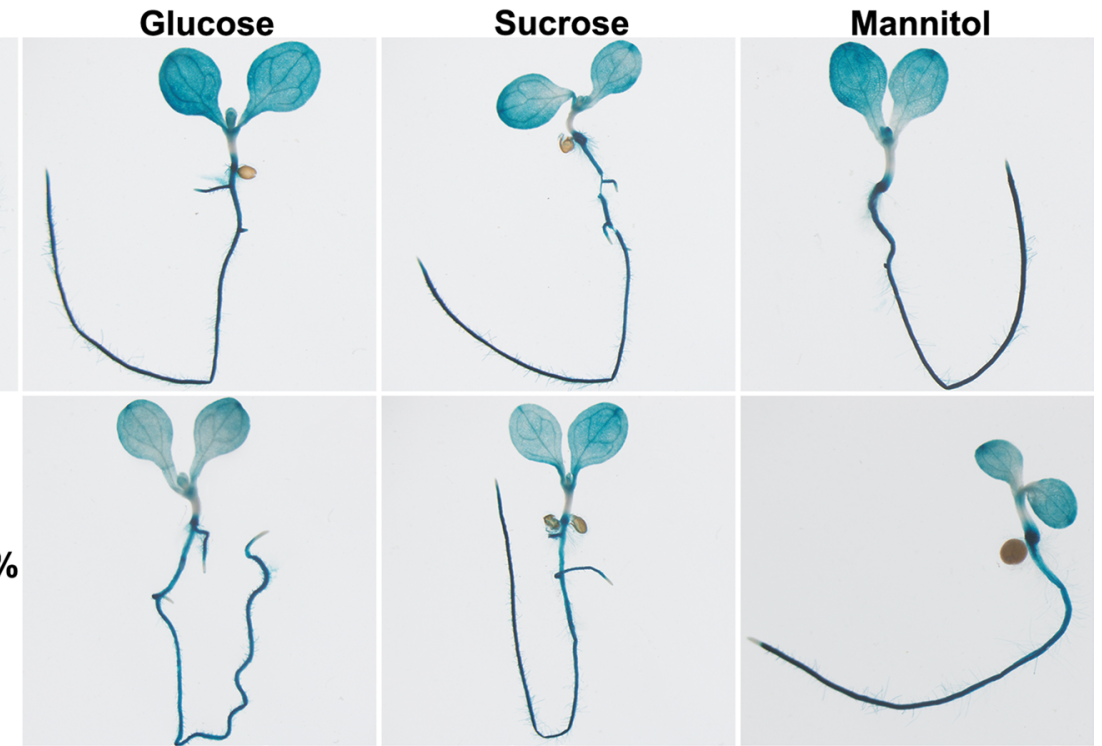

Fig. 5 Promoter and expression pattern of AtCIPK9 in 7-day-old seedlings in the presence or absence of sugars. a Composition of putative cis-acting elements in promoter of AtCIPK9. The promoter of AtCIPK9 is the $2000 \mathrm{bp}$ from the original fragment. b Expression pattern of the AtCIPK9 in 7-day-old seedlings in the presence or absence of sugars. The transcriptional fusion included $3.0 \mathrm{~kb}$ of the $5^{\prime}$-untranslated region of the AtCIPKO fused to the GUS reporter gene used to generate the transgenic lines (ProAtCIPK9:GUS). Different sugar sources (1 or 3\% glucose, or sucrose) were used: mannitol was used as a control for osmotic stress. The images shown are representative of the three biologically independent experiments

In cipk9 seeds, the relative proportion of $\mathrm{C} 20: 1 \Delta 11$ was increased, whereas the relative proportion of $\mathrm{C} 18: 2$ was clearly decreased, compared to WT plants (Fig. 6c).

To examine defects in seedling establishment on halfstrength MS medium, we examined seedlings' generation and establishment in the absence and presence of $1 \%$ sucrose. No significant differences were found between the cipk 9 mutant and WT plants under normal growth conditions (half-strength MS medium with $1 \%$ sucrose), although cipk9 plants were more sensitive to the halfstrength MS medium without sugar supplementation, as they failed to establish roots under this condition. To demonstrate the genetic complementation of AtCIPK9, we transformed mutant plants using the genomic DNA (com-1) and the coding sequence (com-2) of AtCIPK9 under the control of its native promoter. Three independent complementation lines were generated for the allele of cipk9. The expression levels of AtCIPK9 were restored 


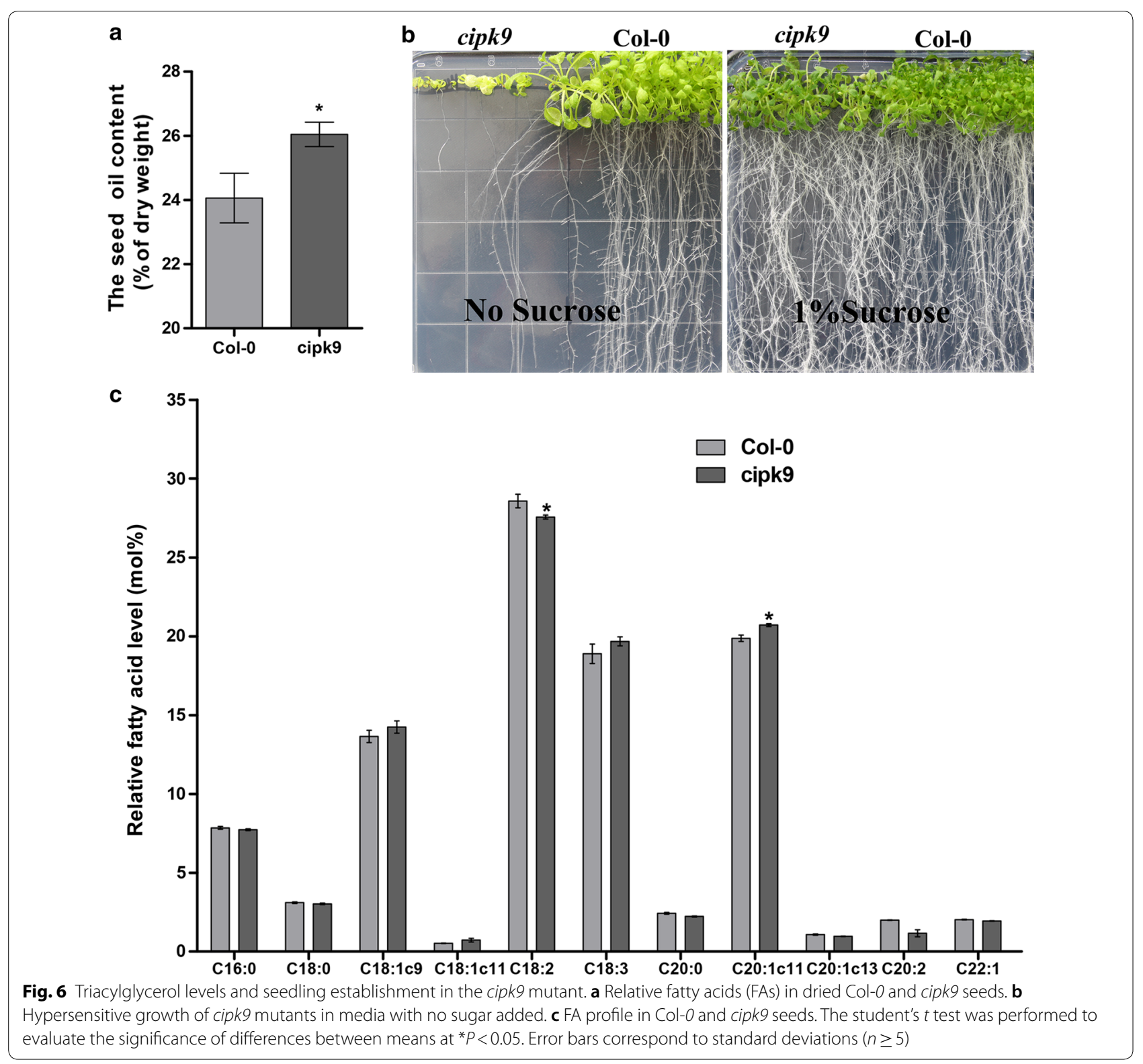

in the three complementation lines (Fig. 7a), and the phenotypes of these three complementation lines were similar to that of WT plants, when grown on half-strength MS medium without sugar supplementation (Fig. 7d). The three transgenic lines showed normal OC (Fig. 7b), although significantly lower than that of cipk 9 mutant plants (Fig. 7c), implying that AtCIPK9 is required for proper OC. These results demonstrated that sugar sensitivity and lipid accumulation in seeds of cipk 9 were due to the disruption of AtCIPK9. Plants appeared normal on the medium lacking sucrose, suggesting that AtCIPK9 is required for proper early seedling establishment.

\section{CBL2 and CBL3 are involved in the upstream regulation of CIPK9}

It has been shown that CBL2 and CBL3 interact with CIPK9 [56]. We o<btained cbl2 (SALK_057048C) and cbl3 (SALK_091827C) mutants from the ABRC Stock Center, and the expressions of CBL2 and CBL3 were, respectively, disrupted in $c b l 2$ and cbl3 mutants [56, 66]. Both mutants showed the typical cipk 9 phenotype on the half-strength MS medium without sugar (Fig. 8a, b), suggesting that CBL2, CBL3, and CIPK9 might work together and play roles in the establishment of seedlings in the absence of sugar. 


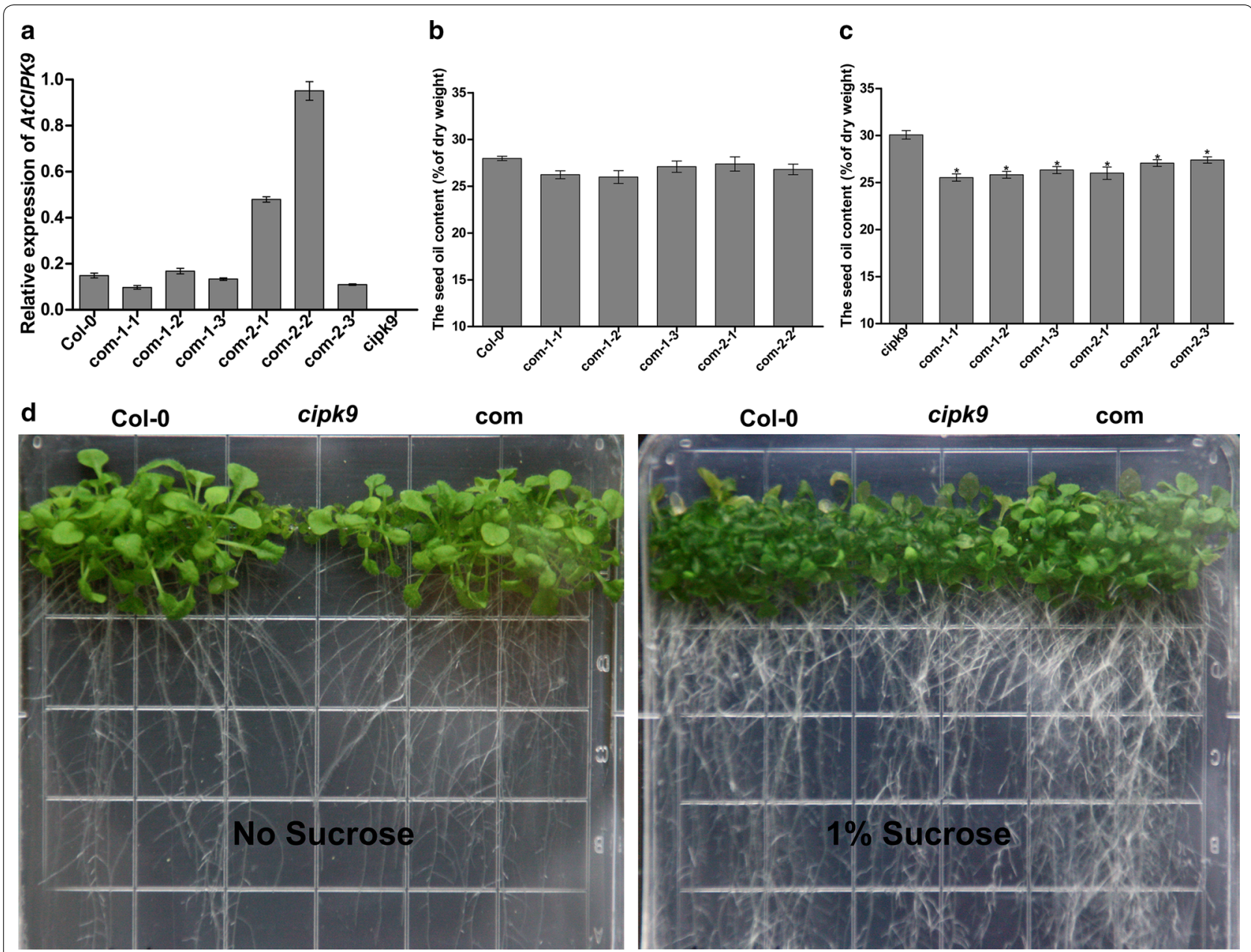

Fig. 7 Complementation of cipk9 mutant and analysis of seed oil content. a AtCIPK9 transcript levels in the transgenic lines. b Seed oil contents of T3 transgenic and wild type (WT, Col-0). c Seed oil contents of T3 transgenic and cipk9 mutants. $\mathbf{d}$ Phenotypes of the complementation lines of cipk9, WT (Col-0), and cipk9 grown in half-strength Murashige and Skoog medium without sucrose for 7 days. The student's $t$ test was performed to determine the significance of differences between means at ${ }^{*} P<0.05$. Error bars indicate standard deviations $(n \geq 5) ; \operatorname{com}-1-1, \mathrm{com}-1-2$, and com-1-3 are three independent promoterAtCIPK9:AtCIPK9 (genomic DNA) transgenic lines; com-2-1, com-2-2, com-2-3 are three independent promoterAtCIPK9:AtCIPK9 (coding sequence) transgenic lines

\section{Discussion}

In eukaryotes, the regulators involved in lipid metabolism and carbohydrate storage in the SNF1/AMPK family of protein kinases are evolutionarily conserved from yeast (SNF1) to mammals (AMPK) and plants (SnRKs). Similar to a previous study that demonstrated the negative regulation of lipid accumulation by SNF1 in yeast [53], we showed that BnCIPK9 and AtCPK9 are negative regulators of $\mathrm{OC}$, and that CIPK9 might also regulate OC by influencing the expression of genes related to lipid metabolism. However, SnRK2.6 is a positive regulator of seed oil production in A. thaliana [41]. Considering that YISnf1 apparently regulates lipid metabolism at the transcriptional level, it might also regulate lipid metabolism by posttranscriptional regulatory processes, including SNF1-dependent translocation and phosphorylation of the key enzymes. When active, Snf1 inhibits the acetylCoA carboxylase (ACCase) [67, 68], and glycerol phosphate acyltransferase (GAPT) [69] activities. In fact, the first conserved function shown for SNF1/AMPK protein kinase among eukaryotes was the regulation of ACCase, the first and rate-limiting enzyme in the de novo synthesis of FAs [67, 68, 70-72]. In fact, ACCase is highly regulated through both transcriptional and biochemical mechanisms, and it is critical for controlling the influx of carbon into FAs, and thus into oil biosynthesis [7379]. Nutritional and metabolic signals, such as glucose limitation and salt stress, are transduced to ACC1 by 


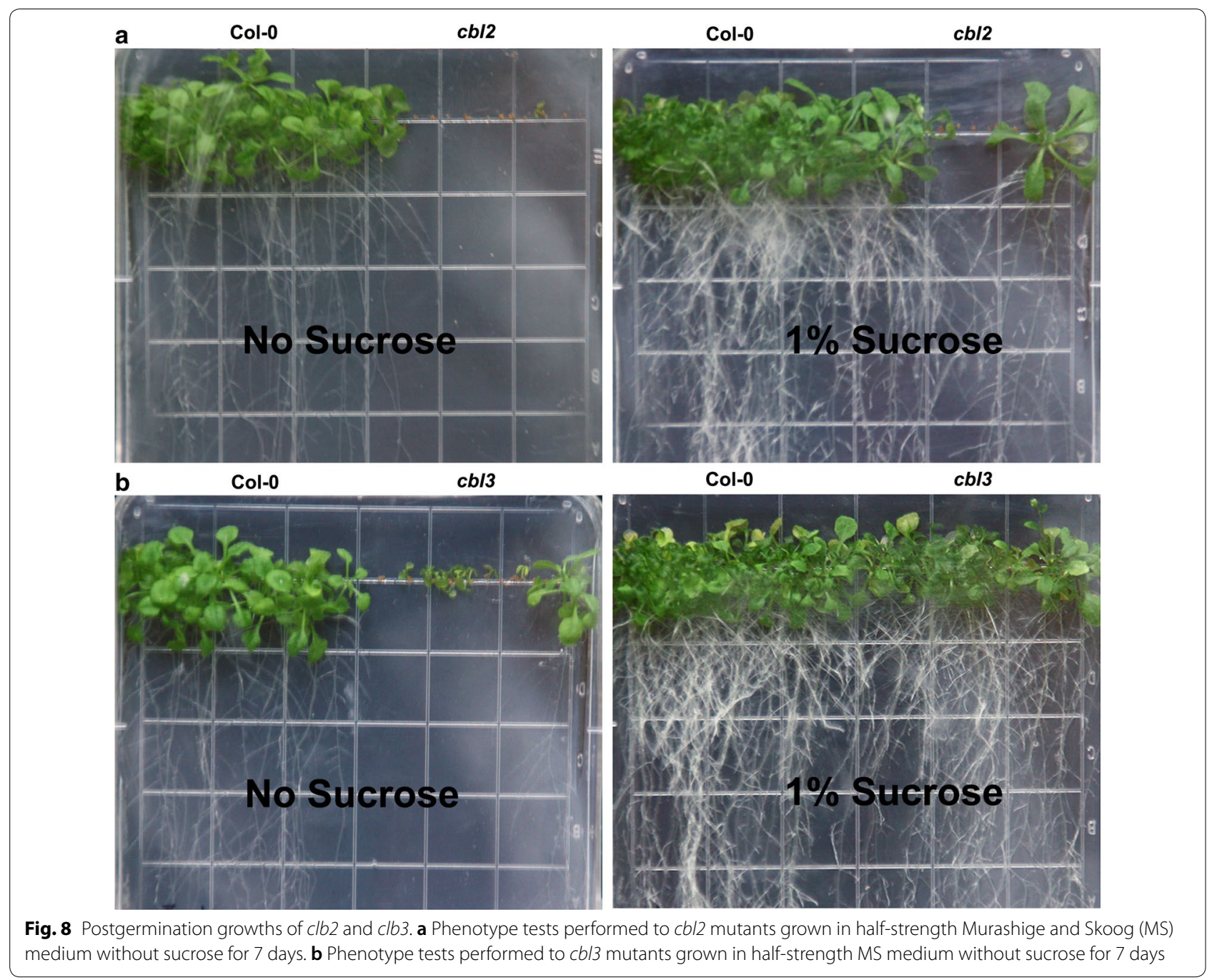

AMPK $[32,35,80]$. In plants, SnRK1 negatively regulates 3-hydroxy-3-methyl-glutaryl-coenzyme A reductase [81], and is supposed to negatively regulate diacylglycerol acyltransferase (DGAT) [82]. A putative tyrosine phosphorylation motif was observed in mammalian DGAT, but no apparent tyrosine phosphorylation site could be found in transient axonal glycoprotein1 [83]. However, visual examination revealed a consensus sequence (X-L200-XK202-X-X-S205-X-X-X-V209), which was identified as the targeting motif, typical of the members of the SnRK1 protein kinase family [84]. Similar to SnRK1 in plants and Snf1 in yeast, CIPK9 might also regulate the activities of these enzymes through protein phosphorylation.

In oilseed plants, an essential function of seed reserves, manifested by OC levels, is to provide energy for postgermination growth until the seedling can perform photosynthesis [7, 85]. We observed a higher OC in cipk9 mutants than in WT plants, but the roots of cipk9 mutant seedlings failed to establish on half- strength MS medium without sugar, which could be recovered by the addition of exogenous sucrose. Thus, cipk 9 resembles the $s d p 1$ mutant, which showed increased OC because of a defect in TAG degradation [13, 86, 87]. During the establishment of seedling roots, resources are mobilized by hydrolysis of lipids and fatty acid catabolism ( $\beta$-oxidation), which connected to sugar biosynthesis via the glyoxylate cycle [15]. It has been shown that seedling establishment is compromised in plants with deficient glyoxylate cycle $[88,89]$, gluconeogenesis [90, 91], and transportation of intermediates derived from lipid breakdown [92-96]. The establishment of seedlings could be rescued by the supplementing sucrose to mutants with deficient seed oil catabolism [91], but carbohydrate metabolism [97] was affected during seed development. Furthermore, FAs and FA-derived lipids can facilitate successful seed germination and seedling establishment [6]. 
Glycolysis, tricarboxylic acid cycle, oxidative phosphorylation, and mitochondrial electron transport were reported to be significantly upregulated in germinating seeds of $A$. thaliana, indicating that respiration is one of the essential processes to facilitating seed germination [98, 99]. The cipk9 mutants grown in the medium supplemented with sugar showed similar root length to WT plants, indicating that plants are capable of sucrose catabolism. Transcript analysis indicated that AtCIPK9 has high expression in root, flower, developing silique, and young seedlings [54-56]. Glycolysis and gluconeogenesis are important biological process for providing energy and structural components, which is critical for seedling establishment. These results clearly show that AtCIPK9 plays an important role during germination and the later phase of seedling establishment. Thus, cipk 9 seeds might not be able to fully convert lipids to sucrose.

The expression of BnCIPK9 and AtCIPK9 are induced by sugar starvation and suppressed by sugar supplementation, which is similar to the regulation pattern of DIN6, STP1, and $\alpha-A m y 3[24,58,100,101]$. In the present research, we attempted to identify the cis-acting elements required for the suppression of $B n C I P K 9$ by sugar. In silico assays showed that $B n C I P K 9$ and $\alpha-A m y 3, S T P 1$, and DIN6 promoters shared two TATCCA cis-acting elements and $\mathrm{G}$ boxes $[24,58,100]$. The TATCCA ciselement was identified as the binding site for OsMYB2, and is essential for the regulation of $\alpha-A m y 3$ in rice by sugar [68]. Moreover, the arrangement of these elements in BnCIPK9 (in tandem and separated by $252 \mathrm{bp}$ and $516 \mathrm{bp}$ ) is different from that in $\alpha$-Amy3 (separated $15 \mathrm{bp}$ ) [57]. As for AtCIPK9, the promoter JCSDP1 also carries one TATCCA element; gene expression is sugardependent and it is especially responsive to sucrose and fructose [95]. Thus, the TATCCA element is an interesting candidate for better understanding the mechanism by which sugar regulates $B n C I P K 9$. The transcriptomic analysis of Cookson et al. [102] suggested that sucrose affects gene expression via multiple routes at the transcription level. One of the transcriptional responses to changes in carbon status is the signaling via SnRK1 accounts. The I-box (light regulated) and ABRE-like motifs are enriched in all the clusters of gene induced by carbon depletion, and promoters of BnCIPK9 and AtCIPK9 also carry several I-box elements.

Previous studies indicated that CIPK15 induced the accumulation of SnRK1A, which promotes the interaction between MYBS1 and the TA box and regulates the transcription level of $\alpha$-Amy3 [103, 104]. In the beginning of germination, signals of nutrient starvation induce the nuclear import and expression of MYBS1, which activates target gene expression by binding to the TA box in the promoters of the target gene. In rice, during early postgermination growth, MYBS1 plays an important role in the common nutrient-starvation signaling pathway, possibly through CBL-CIPK15-SnRK1A-dependent sugar-starvation signaling pathway [30, 103, 104]. Moreover, SnRK1 has been reported to play a pivotal role in linking stress, development, and sugar signaling at the level of gene expression, which indicates its crucial regulatory effect on plant metabolism, energy balance, and growth [24]. These findings suggest that function conservation in SnRK1/SNF1/AMPK has played an important role in sugar-mediated regulation across eukaryotes throughout evolution. Consistent with the results obtained for rice, the promoter region of $B n C I P K 9$ would allow the identification of cis-acting elements and trans-acting factors involved in sugar and lipid accumulation in rapeseed.

\section{Conclusion}

Overall, this study shows that BnCIPK9 and AtCIPK9 encode a protein kinase involved in sugar-related response and are important regulatory elements in energy storage. Gene AtCIPK9 has a significant effect on early seedling root establishment in $A$. thaliana. Although it has been confirmed that sugars suppress the repression of $B n C I P K 9$ and $A t C I P K 9$, it is necessary, and would be interesting, to explore the roles of $B n C I P K 9$ and AtCIPK9 in the sugar signaling pathway and to identify the downstream targets of CIPK9 in plants. In the future, genomewide transcriptomic and proteomic analyses combined with in vitro and in vivo studies of proteinprotein interaction should provide more information on the function of CIPK9 in the sugar response.

\section{Methods}

\section{Plants material and growth condition}

Rapeseed parent plants with high-oil (P1) and low-oil (P2) contents, and the $F_{2}$ populations resulting from them were grown in a randomized array in Saskatoon, Canada. The dataset consists of seven lines of high OC (H4, H12, H41, H64, H86, H133, H154) and their pool (HP), seven lines of low OC (L89, L161, L179, L267, L270, L306, L307) and their pool (LP), and hybrids of the highand low-oil lines (P1P2, P2P1), all belonging to $F_{2}$ populations. The $B$. napus transgenic lines used for the analysis of $\mathrm{OC}$ were grown during the normal growing season at the experimental station of Huazhong Agricultural University, China. Regular field management was conducted according to local agricultural practices.

Arabidopsis thaliana ecotype Columbia (Col-O) was grown at $22{ }^{\circ} \mathrm{C}$ in growth chambers under $16 \mathrm{~h}$ of light and $8 \mathrm{~h}$ of darkness. A. thaliana Col- 0 and its cipk9, $c b l 2$, and $c b l 3$ mutants were ordered from the Arabidopsis Biological Resource Center (ABRC), USA (http://www.arabi 
dopsis.org/). Genomic DNA was extracted from plants grown in soil for 1 month. Homozygous lines of AtCIPK 9 (SALK_058629), AtCBL2 (SALK_057048C), and AtCBL3 (SALK_091827C) mutants were screened by PCR using LBb1.3 and three gene-specific primers (Additional file 1: Table S1). We chose etiolated seedlings grown on halfstrength MS medium (Caisson Laboratories Inc., UT, USA) without supplementary sugar as a model system for carbon starvation. The A. thaliana seeds (Col-0, cipk9, com-1, com-2, cbl2, cbl3) were surface sterilized, and then randomly sown on half-strength MS agarose plates with $1 \%$ sucrose, or without sugar.

\section{Construction of plasmids}

All primers for cloning and vector construction are listed in Additional file 1: Table S1. Both complementation lines of cipk9, with the AtCIPK9 genomic sequence (com-1:promoterAtCIPK9:gDNA(AtCIPK9)) and coding sequence (com-2:promoterAtCIPK9:CDS(AtCIPK9)) driven by its own promoter, were cloned into the PCAMBIA1300 vector, and were transformed into the cipk9 (SALK_058629) mutant by floral dipping. Transgenic lines were selected on half-strength MS medium containing $1 \%$ agarose and supplemented with $40 \mu \mathrm{g} \mathrm{mL}$ hygromycin, and T3 seedlings were planted on vertical half-strength MS agarose plates with or without $1 \%$ sucrose for 7 days. The deletion of the NAF motif and substitution of threonine with aspartate within the activation loop of $B n C I P K 9$ were performed via gene splicing by overlap extension PCR in vitro mutagenesis. To obtain $B n C I P K 9$-overexpression transgenic lines, the kinase domain of CIPK9T178D was cloned a pC2300 vector harboring BnNapin promoter and a CaMV35 s polyA addition sequence, and transformed into rapeseed variety 5572 (wild type). The rapeseed transgenic lines were generated using $A$. tumefaciens-mediated transformation $[105,106]$. Primers used in the positive transplant test are listed in Additional file 1: Table S1. The four independent transgenic lines mentioned above (at least eight plants per line) were selected in the T2 generation and used in the current study.

\section{Construction of promoter:GUS transgenic plants}

The BnCIPK9 promoter1 (3050 bp) and BnCIPK9 promoter2 (3372 bp) fragments were amplified with a forward primer containing a SalI restriction site and a reverse primer containing a $\mathrm{BamHI}$ restriction site, and then cloned into the pCXGUS-P vector in front of the GUS coding sequence. The AtCIPK9 promoter fragment (3000 bp) was amplified and cloned into pCXGUS$\mathrm{P}$ in front of the GUS coding sequence using SalI and BamHI sites. Multiple lines of BnCIPK9 promoter1:GUS, $B n C I P K 9$ promoter2:GUS, and AtCIPK9 promoter:GUS seedlings were generated, and the homozygous lines were isolated and used to verify the reproducibility of GUS staining patterns. The seeds of T3 transgenic lines (BnCIPK9promoter1:GUS, BnCIPK9 promoter2:GUS and AtCIPK9 promoter:GUS) were surface-sterilized, and then randomly sown on half-strength MS agarose plates with $1 \%$ sucrose, $3 \%$ sucrose, $1 \%$ glucose, $3 \%$ glucose, $1 \%$ mannitol (Sigma-Aldrich, MO, USA), 3\% mannitol or without sugar supplementation. The plates were incubated for 1 week $\left(22^{\circ} \mathrm{C} / 18^{\circ} \mathrm{C} ; 16 / 8 \mathrm{~h}\right.$ day/night photoperiod). Analysis of GUS activity in different tissues of T3 transgenic lines was performed as described previously [107].

\section{Quantification of GUS activity}

The expression pattern of the promoters was determined by a quantitative GUS activity assay using the total protein extracted from plants grown for 7 days on halfstrength MS without sugar supplementation or with $1 \%$ sucrose, $3 \%$ sucrose, $1 \%$ glucose, $3 \%$ glucose, $1 \%$ mannitol, or with $3 \%$ mannitol. Fluorometric GUS assays to measure GUS activity in plant seedlings were performed according to Jefferson [107]. The total protein concentration in plant extracts was determined according to Bradford [108] using bovine serum albumin as the standard. Fluorescence was recorded using Tecan Infinite M200 PRO (Tecan Group Ltd., Switzerland) [109].

\section{Fatty acid and lipid analysis in A. thaliana}

Both fatty acid composition and lipid content of Col0 , cipk 9 , com-1, and com-2 plants were analyzed by gas chromatography (GC) following previously published procedures [6]. About 100 dry seeds of each background were weighted for the first biological repeat, and at least three technical repeats were included in each experiment. The samples were transmethylated at $90{ }^{\circ} \mathrm{C}$ for $60 \mathrm{~min}$, and $200 \mu \mathrm{g}$ of heptadecanoic acid (C17:0) was used as the quantitative internal standard. After cooling the tubes to room temperature, $1.5 \mathrm{mLof} 0.9 \% \mathrm{NaCl}(\mathrm{w} / \mathrm{v})$ was added to the mix, and the FA methyl esters (FAMEs) were extracted twice in $1 \mathrm{~mL}$ of hexane. Samples were then analyzed with GC using a flame ionization detector (FID) on Agilent 6890 (Agilent, santa Clara, CA, USA), employing helium as the carrier gas.

\section{Analysis of $O C$ in rapeseed}

The total OC in rapeseed seeds was measured in Foss NIR-System 5000 near-infrared reflectance spectroscope (NIR-Systems, Inc., Silver Spring, MD, USA) [110], using the parameters described by Gan et al. [111]. At least eight biological replicates from each transgenic line were used. 


\section{RNA isolation and quantitative real-time PCR}

Total RNA was isolated from the plant samples (root, stem, flower, bud, 24DAP seed, and 24DAP silique wall of the parent P1) and used for quantitative real-time PCR (qRT-PCR). The RNA contained in each sample was quantified in a NanoDrop2000 and its integrity was checked on $1.2 \%(\mathrm{w} / \mathrm{v})$ agarose gels. The qRT-PCR assay was performed on a CFX96 real-time PCR machine (Bio-Rad, USA) using gene-specific primers and the SYBR Green PCR Master Mix (Applied Biosystems), according to the manufacturer's instructions. For the internal control, we used species-specific actin primer sets for B. napus and A. thaliana. All qRT-PCR experiments were performed in triplicate for each sample from three independent biological replicates. All primers for the qRT-PCR are listed in the Additional file 1: Table S1.

\section{Statistical analysis}

To ensure reproducibility, the experiments were performed using at least three biological triplicates. All quantitative data were expressed as the mean value with corresponding standard deviation (SD), and statistical differences between means was evaluated using the Student's $t$ test, at significance levels of $P<0.05$ and $P<0.01$.

\section{Additional file}

Additional file 1: Table S1. Primers used in the present study.

\section{Abbreviations \\ ACC1: acetyl CoA carboxylase; AMPK: AMP protein kinase; bp: base pairs; CBL: calcineurin B-like protein; CIPK: CBL-interacting protein kinase; TAG: triacylg- lycerol; DAP: day after pollination; FA: fatty acid; GC: gas chromatography; MS: Murashige and Skoog; OC: seed oil content; PCR: polymerase chain reaction; SNF1: sucrose non-fermenting; SnRK: sucrose non-fermenting kinase.}

\section{Authors' contributions}

GYL, YH, JG, YYP, WYP, and NW performed the experiments and analyzed the data. JXS and JTZ conceived and supervised the study. JXT, TDF, CZM, BY, and JW participated in its design. YLG mainly wrote the manuscript. JXS and JTZ helped to revise the manuscript. All authors read and approved the final manuscript.

\section{Author details \\ ${ }^{1}$ National Key Laboratory of Crop Genetic Improvement/National Engi- neering Research Center of Rapeseed, Huazhong Agricultural University, Wuhan 430070, China. ${ }^{2}$ National Research Council Canada, Saskatoon, SK S7N0 W9, Canada. ${ }^{3}$ Crop Research Institute of TIANJIN Academy of Agricul- tural Sciences, Tianjin 300384, China.}

\section{Acknowledgements}

We thank Q Li, LX Zhu, and HM Wang for their assistance with plant material collection and data analysis. We are also grateful to Prof. Zuoxiong Liu for editing the English language of the manuscript.

\section{Competing interests}

The authors declare that they have no competing interests.

\section{Availability of data and materials}

The datasets supporting the conclusions of this article are included within the article and its Additional file.

\section{Consent for publication}

Not applicable.

\section{Ethics approval and consent to participate}

Not applicable.

\section{Funding}

This research was financially supported by the National Key Research and Development Program of China (Grant Number 2016YFD0101300) and the Program for Modern Agricultural Industrial Technology System (Grant Number CARS-13).

\section{Publisher's Note}

Springer Nature remains neutral with regard to jurisdictional claims in published maps and institutional affiliations.

Received: 5 January 2017 Accepted: 19 April 2018

Published online: 02 May 2018

References

1. Sturm A. Invertases. Primary structures, functions, and roles in plant development and sucrose partitioning. Plant Physiol. 1999;121(1):1-8.

2. Lunn JE, MacRae E. New complexities in the synthesis of sucrose. Curr Opin Plant Biol. 2003;6(3):208-14.

3. Koch K. Sucrose metabolism: egulatory mechanisms and pivotal roles in sugar sensing and plant development. Curr Opin Plant Biol. 2004;7(3):235-46.

4. Roitsch T, González MC. Function and regulation of plant invertases: sweet sensations. Trends Plant Sci. 2004;9(12):606-13.

5. Bewley JD, Black M. Seeds. Boston: Springer; 1994. p. 1-33.

6. Li Y, Beisson F, Pollard M, Ohlrogge J. Oil content of Arabidopsis seeds: the influence of seed anatomy, light and plant-to-plant variation. Phytochemistry. 2006;67(9):904-15.

7. Fait A, Angelovici R, Less H, Ohad I, Urbanczyk-Wochniak E, et al. Arabidopsis seed development and germination is associated with temporally distinct metabolic switches. Plant Physiol. 2006;142(3):839-54.

8. Carrera E, Holman T, Medhurst A, Peer W, Schmuths H, et al. Gene expression profiling reveals defined functions of the ATP-binding cassette transporter COMATOSE late in phasell of germination. Plant Physiol. 2007;143(4):1669-79.

9. Bassel GW, Fung P, TfF Chow, Foong JA, Provart NJ, et al. Elucidating the germination transcriptional program using small molecules. Plant Physiol. 2008;147(1):143-55.

10. Mansfield S, Briarty L. Cotyledon cell development in Arabidopsis thaliana during reserve deposition. Can J Bot. 1992;70(1):151-64.

11. Eastmond PJ, Rawsthorne S. Coordinate changes in carbon partitioning and plastidial metabolism during the development of oilseed rape embryos. Plant Physiol. 2000;122(3):767-74.

12. Chia TY, Pike MJ, Rawsthorne S. Storage oil breakdown during embryo development of Brassica napus (L.). J Exp Bot. 2005;56(415):1285-96.

13. Eastmond PJ. SUGAR-DEPENDENT1 encodes a patatin domain triacylglycerol lipase that initiates storage oil breakdown in germinating Arabidopsis seeds. Plant Cell. 2006;18(3):665-75.

14. Graham IA. Seed storage oil mobilization. Annu Rev Plant Biol. 2008:59:115-42.

15. Theodoulou FL, Eastmond PJ. Seed storage oil catabolism:a story of give and take. Curr Opin Plant Biol. 2012;15(3):322-8.

16. Quettier AL, Eastmond PJ. Storage oil hydrolysis during early seedling growth. Plant Physiol Biochem. 2009;47(6):485-90.

17. Gibson SI. Control of plant development and gene expression by sugar signaling. Curr Opin Plant Biol. 2005;8(1):93-102.

18. Rolland F, Baenagonzalez E, Sheen J. Sugar sensing and signaling in plants: conserved and novel mechanisms. Annu Rev Plant Biol. 2006:57:675-709. 
19. Smeekens S, Ma J, Hanson J, Rolland F. Sugar signals and molecular networks controlling plant growth. Curr Opin Plant Biol. 2010;13(3):273-8.

20. Koch KE. Carbohydrate-modulated gene expression in plants. Annu Rev Plant Biol. 1996;47(1):509-40.

21. Borisjuk L, Rolletschek H, Wobus U, Weber H. Differentiation of legume cotyledons as related to metabolic gradients and assimilate transport into seeds. J Exp Bot. 2003;54(382):503-12.

22. Coruzzi G, Bush DR. Nitrogen and carbon nutrient and metabolite signaling in plants. Plant Physiol. 2001;125(1):61-4.

23. Baenagonzalez E. Energy signaling in the regulation of gene expression during stress. Mol Plant. 2010;3(2):300-13.

24. Baenagonzalez E, Rolland F, Thevelein JM, Sheen J. A central integrator of transcription networks in plant stress and energy signalling. Nature. 2007;448(7156):938-42.

25. Xiong Y, McCormack M, Li L, Hall Q, Xiang C, et al. Glucose-TOR signalling reprograms the transcriptome and activates meristems. Nature. 2013;496(7444):181-6.

26. Sheen J. Discover and connect cellular signaling. Plant Physiol. 2010;154(2):562-6.

27. Hanson J, Smeekens S. Sugar perception and signaling-an update. Curr Opin Plant Biol. 2009;12(5):562-7.

28. LV Y, Yang M, Hu D, Yang ZY, Ma SQ, et al. The OsMYB30 transcription factor suppresses cold tolerance by interacting with a JAZ protein and suppressing $\beta$-amylase expression. Plant Physiol. 2017;173(2):1475-91.

29. Lastdrager J, Hanson J, Smeekens S. Sugar signals and the control of plant growth and development. J Exp Bot. 2014;65(3):799-807.

30. Lu CA, Lin CC, Lee KW, Chen JL, Huang LF, et al. The SnRK1A protein kinase plays a key role in sugar signaling during germination and seedling growth of rice. Plant Cell. 2007;19(8):2484-99.

31. Hardie DG, Carling D. The AMP-activated protein kinase. Eur J Biochem. 1997;246(2):259-73.

32. Hardie DG, Carling D, Carlson M. The AMP-activated/SNF1 protein kinase subfamily: metabolic sensors of the eukaryotic cell? Annu Rev Biochem. 1998;67(1):821-55

33. Carling D. The AMP-activated protein kinase cascade-a unifying system for energy control. Trends Biochem Sci. 2004;29(1):18-24.

34. Hardie DG. AMPK and SNF1: snuffing out stress. Cell Metab. 2007:6(5):339-40.

35. Hedbacker K, Carlson M. SNF1/AMPK pathways in yeast. Front Biosci. 2008;13(7):2408-20.

36. Halford NG, Hey S, Jhurreea D, Laurie S, McKibbin RS, et al. Metabolic signalling and carbon partitioning: role of Snf1-related (SnRK1) protein kinase. J Exp Bot. 2003;54(382):467-75.

37. Benschop JJ, Millenaar FF, Smeets ME, Van ZM, Voesenek LA, et al. Abscisic acid antagonize sethylene-induced hyponastic growth in Arabidopsis. Plant Physiol. 2007;143(2):1013-23

38. Polge C, Thomas M. SNF1/AMPK/SnRK1 kinases, global regulators at the heart of energy control? Trends Plant Sci. 2007;12(1):20-8

39. Baenagonzalez E, Sheen J. Convergent energy and stress signaling. Trends Plant Sci. 2008;13(9):474-82.

40. Halford NG, Hey SJ. Snf1-related protein kinases (SnRKs) act within an intricate network that links metabolic and stress signalling in plants. Biochem J. 2009:419(2):247-59.

41. Zheng Z, Xu X, Crosley RA, Greenwalt SA, Sun Y, et al. The protein kinase SnRK2.6 mediates the regulation of sucrose metabolism and plant growth in Arabidopsis. Plant Physiol. 2010;153(1):99-113.

42. Hrabak EM, Chan CW, Gribskov M, Harper JF, Choi JH, et al. The Arabidopsis CDPK-SnRK superfamily of protein kinases. Plant Physiol. 2003;132(2):666-80.

43. Kudla J, Xu Q, Harter K, Gruissem W, Luan S. Genes for calcineurin B-like proteins in Arabidopsis are differentially regulated by stress signals. Proc Natl Acad Sci. 1999:96(8):4718-23.

44. Shi J, Kim KN, Ritz O, Albrecht V, Gupta R, et al. Novel protein kinases associated with calcineurin B-like calcium sensors in Arabidopsis. Plant Cell. 1999;11(12):2393-405.

45. Kim KN, Cheong YH, Gupta R, Luan S. Interaction specificity of Arabidopsis calcineurin B-like calcium sensors and their target kinases. Plant Physiol. 2000;124(4):1844-53.

46. Luan S, Kudla J, Rodriguez-Concepcion M, Yalovsky S, Gruissem W. Calmodulins and calcineurin B-like proteins calcium sensors for specific signal response coupling in plants. Plant Cell. 2002;14(Suppl 1):S389-400.

47. Batistic $\mathrm{O}$, Kudla J. Integration and channeling of calcium signaling through the CBL calcium sensor/CIPK protein kinase network. Planta. 2004:219(6):915-24

48. Batistič O, Kudla J. Plant calcineurin B-like proteins and their interacting protein kinases. Biochim Biophys Acta. 2009;1793(6):985-92.

49. Kolukisaoglu Ü, Weinl S, Blazevic D, Batistic O, Kudla J. Calcium sensors and their interacting protein kinases: genomics of the Arabidopsis and rice CBL-CIPK signaling networks. Plant Physiol. 2004;134(1):43-58.

50. Luan S. The CBL-CIPK network in plant calcium signaling. Trends Plant Sci. 2009;14(1):37-42.

51. Saravitz CH, Raper CD. Responses to sucrose and glutamine by soybean embryos grown in vitro. Physiol Plant. 1995;93(4):799-805.

52. Pipolo AE, Sinclair TR, Camara G. Protein and oil concentration of soybean seed cultured in vitro using nutrient solutions of differing glutamine concentration. Ann Appl Biol. 2004;144(2):223-7.

53. Seip J, Jackson R, He H, Zhu Q, Hong SP. Snf1 is a regulator of lipid accumulation in Yarrowia lipolytica. Appl Environ Microb. 2013;79(23):7360-70.

54. Pandey GK, Cheong YH, Kim BG, Grant JJ, Li L, et al. CIPK9: a calcium sensor-interacting protein kinase required for low-potassium tolerance in Arabidopsis. Cell Res. 2007;17(5):411-21.

55. Gong D, Gong Z, Guo Y, Zhu JK. Expression, activation, and biochemical properties of a novel Arabidopsis protein kinase. Plant Physiol. 2002;129(1):225-34

56. Liu LL, Ren HM, Chen LQ, Wang Y, Wu WH. A protein kinase, calcineurin B-like protein-interacting protein kinase9, interacts with calcium sensor calcineurin B-like protein3 and regulates potassium homeostasis under low-potassium stress in Arabidopsis. Plant Physiol. 2013;161(1):266-77.

57. Lu CA, Lim EK, Yu SM. Sugar response sequence in the promoter of a rice a-amylase gene serves as a transcriptional enhancer. J Biol Chem. 1998;273(17):10120-31.

58. Lu CA, Ho ThD, Ho SL, Yu SM. Three novel MYB proteins with one DNA binding repeat mediate sugar and hormone regulation of a-amylase gene expression. Plant Cell. 2002;14(8):1963-80.

59. Baranowskij N, Frohberg C, Prat S, Willmitzer L. A novel DNA binding protein with homology to Myb oncoproteins containing only one repeat can function as a transcriptional activator. EMBO J. 1994;13(22):5383-92.

60. Manzara T, Carrasco P, Gruissem W. Developmental and organspecific changes in promoter DNA-protein interactions in the tomato rbcS gene family. Plant Cell. 1991;3:1305-16.

61. Stålberg K, Ellerstöm M, Ezcurra I, Ablov S, Rask L. Disruption of an overlapping E-box/ABRE motif abolished high transcription of the napA storage-protein promoter in transgenic Brassica napus seeds. Planta. 1996:199(4):515-9.

62. Hartmann U, Sagasser M, Mehrtens F, Stracke R, Weisshaar B. Differential combinatorial interactions of cis-acting elements recognized by R2R3MYB, BZIP, and BHLH factors control light-responsive and tissue-specific activation of phenylpropanoid biosynthesis genes. Plant Mol Biol. 2005;57(2):155-71.

63. Huang $N$, Sutliff TD, Litts JC et al Classification and characterization of the rice a-amylase multigene family. Plant Mol Biol. 1990;14(5):655-68.

64. Harmer SL, Hogenesch JB, Straume M, Chang HS, Han B, Zhu T, Wang $X$, Kreps JA, Kay SA. Orchestrated transcription of key pathways in Arabidopsis by the circadian clock. Science. 2000;290:2110-3.

65. Li Y, Lee KK, Walsh S, Smith C, Hadingham S, Sorefan K, Cawley G, Bevan MW. Establishing glucose- and ABA-regulated transcription networks in Arabidopsis by microarray analysis and promoter classification using a relevance vector machine. Genome Res. 2006;16:414-27.

66. Tang RJ, Liu H, Yang Y, Yang L, Gao XS, et al. Tonoplast calcium sensors CBL2 and CBL3 control plant growth and ion homeostasis through regulating V-ATPase activity in Arabidopsis. Cell Res. 2012;22(12):1650-65.

67. Mitchelhill Kl, Stapleton D, Gao G, House C, Michell B, et al. Mammalian AMP-activated protein kinase shares structural and functional homology with the catalytic domain of yeast SNF1 protein kinase. J Biol Chem. 1994;269(4):2361-4

68. Woods A, Munday MR, Scott J, Yang X, Carlson M, et al. Yeast SNF1 is functionally related to mammalian AMP-activated protein 
kinase and regulates acetyl-CoA carboxylase in vivo. J Biol Chem. 1994;269(30):19509-15.

69. Muoio DM, Seefeld K, Witters LA, Coleman RA. AMP-activated kinase reciprocally regulates triacylglycerol synthesis and fatty acid oxidation in liver and muscle: evidence that sn-glycerol-3-phosphate acyltransferase is a novel target. Biochem J. 1999;338(3):783-91.

70. Shi S, Chen Y, Siewers V, Nielsen J. Improving production of malonyl coenzyme A-derived metabolites by abolishing Snf1-dependent regulation of Acc1. MBio. 2014:5(3):e01130-01114.

71. Hofbauer HF, Schopf FH, Schleifer H, Knittelfelder OL, Pieber B, et al. Regulation of gene expression through a transcriptional repressor that senses acyl-chain length in membrane phospholipids. Dev Cell. 2014;29(6):729-39.

72. Tehlivets O, Scheuringer K, Kohlwein SD. Fatty acid synthesis and elongation in yeast. BBA. 2007;1771(3):255-70.

73. Mcglew K, Shaw V, Zhang M, Kim RJ, Yang W, et al. An annotated database of Arabidopsis mutants of acyl lipid metabolism. Plant Cell Rep. 2015;34(4):519-32.

74. Li-Beisson Y, Shorrosh B, Beisson F, Andersson MX, Arondel V, et al. Acyl-lipid metabolism. Arabidopsis Book. 2013;11(8):e0133.

75. Feria Bourrellier AB, Valot B, Guillot A, Ambardbretteville F, Vidal J, et al. Chloroplast acetyl-CoA carboxylase activity is 2-oxoglutarateregulated by interaction of PII with the biotin carboxyl carrier subunit. Proc Natl Acad Sci. 2010;107(1):502-7.

76. Andre C, Shanklin J. Feedback regulation of plastidic acetyl-CoA carboxylase by 18:1-acyl carrier protein in Brassica napus. Proc Natl Acad Sci. 2012:109(25):10107-12

77. Nikolau BJ, Ohlrogge JB, Wurtele ES. Plant biotin-containing carboxylases. Arch Biochem Biophys. 2003:414(2):211-22.

78. Troncosoponce MA, Kilaru A, Cao X, Durrett TP, Fan J, et al. Comparative deep transcriptional profiling of four developing oilseeds. Plant $J$. 2011;68(6):1014-27.

79. Ruuska SA, Girke T, Benning C, Ohlrogge JB. Contrapuntal networks of gene expression during Arabidopsis seed filling. Plant Cell. 2002;14(6):1191-206.

80. Carling D, Aguan K, Woods A, Verhoeven A, Beri RK, et al. Mammalian AMP-activated protein kinase is homologous to yeast and plant protein kinases involved in the regulation of carbon metabolism. J Biol Chem. 1994;269(15):11442-8.

81. Dale S, Arró M, Becerra B, Morrice NG, Boronat A, et al. Bacterial expression of the catalytic domain of 3-hydroxy-3-methylglutarylCoA reductase (Isoform HMGR1) from Arabidopsis thaliana, and its inactivation by phosphorylation at Ser577 by Brassica oleracea 3-hydroxy-3-methylglutaryl-CoA reductase kinase. Eur J Biochem. 1995;233(2):506-13

82. Xu J, Francis T, Mietkiewska E, Giblin EM, Barton DL, et al. Cloning and characterization of an acyl-CoA-dependent diacylglycerol acyltransferase 1 (DGAT1) gene from Tropaeolum majus, and a study of the functional motifs of the DGAT protein using site-directed mutagenesis to modify enzyme activity and oil content. Plant Biotechnol J. 2008:6(8):799-818.

83. Cases S, Smith SJ, Zheng YW, Myers HM, Lear SR, et al. Identification of a gene encoding an acyltransferase, a key enzyme in triacylglycerol synthesis. Proc Natl Acad Sci. 1998;95(22):13018-23.

84. Zou JT, Wei YD, Jako C, Kumar A, Selvaraj G, et al. The Arabidopsis thaliana TAG1 mutant has a mutation in a diacyglycerol acyltransferase gene. Plant J. 1999;19(6):645-53.

85. Pritchard SL, Charlton WL, Baker A, Graham IA. Germination and storage reserve mobilization are regulated independently in Arabidopsis. Plant J. 2002;31(5):639-47.

86. Eastmond PJ. MONODEHYROASCORBATE REDUCTASE4 is required for seed storage oil hydrolysis and postgerminative growth in Arabidopsis. Plant Cell. 2007;19(4):1376-87.

87. Kim MJ, Yang SW, Mao HZ, Veena SP, Yin JL, et al. Gene silencing of sugar-dependent 1 (JCSDP1), encoding a patatin-domain triacylglycerol lipase, enhances seed oil accumulation in Jatropha curcas. Biotechnol Biofuels. 2014;7(1):1

88. Eastmond PJ, Germain V, Lange PR, Bryce JH, Smith SM, et al. Postgerminative growth and lipid catabolism in oilseeds lacking the glyoxylate cycle. Proc Natl Acad Sci. 2000;97(10):5669-74.
89. Cornah JE, Germain V Ward JL, Beale MH, Smith SM. Lipid utilization, gluconeogenesis, and seedling growth in Arabidopsis mutants lacking the glyoxylate cycle enzyme malate synthase. J Biol Chem. 2004;279(41):42916-23.

90. Rylott EL, Gilday AD, Graham IA. The gluconeogenic enzyme phosphoenolpyruvate carboxykinase in Arabidopsis is essential for seedling establishment. Plant Physiol. 2003:131(4):1834-42.

91. Pinfield-Wells H, Rylott EL, Gilday AD, Graham S, Job K, et al. Sucrose rescues seedling establishment but not germination of Arabidopsis mutants disrupted in peroxisomal fatty acid catabolism. Plant J. 2005;43(6):861-72.

92. Hayashi M, Toriyama K, Kondo M, Nishimura M. 2,4-Dichlorophenoxybutyric acid-resistant mutants of Arabidopsis have defects in glyoxysomal fatty acid $\beta$-oxidation. Plant Cell. 1998;10(2):183-95.

93. Footitt S, Slocombe SP, Larner V, Kurup S, Wu Y, et al. Control of germination and lipid mobilization by COMATOSE, the Arabidopsis homologue of human ALDP. EMBO J. 2002;21(12):2912-22.

94. Lawand S, Dorne AJ, Long D, Coupland G, Mache R, et al. Arabidopsis A BOUT DE SOUFFLE, which is homologous with mammalian carnitine acyl carrier, is required for postembryonic growth in the light. Plant Cell. 2002;14(9):2161-73.

95. Kim S, Yamaoka Y, Ono H, Kim H, Shim D, et al. AtABCA9 transporter supplies fatty acids for lipid synthesis to the endoplasmic reticulum. Proc Natl Acad Sci. 2013:110(2):773-8.

96. Baker A, Graham IA, Holdsworth M, Smith SM, Theodoulou FL. Chewing the fat: $\beta$-oxidation in signalling and development. Trends Plant Sci. 2006;11(3):124-32.

97. Cernac A, Andre C, Hoffmann-Benning S, Benning C. WRI1 is required for seed germination and seedling establishment. Plant Physiol. 2006;141(2):745-57.

98. Narsai R, Law SR, Carrie C, Xu L, Whelan J. In-depth temporal transcriptome profiling reveals a crucial developmental switch with roles for RNA processing and organelle metabolism that are essential for germination in Arabidopsis. Plant Physiol. 2011;157(3):1342-62.

99. Silva AT, Ribone PA, Chan RL, Ligterink W, Hilhorst HW. A predictive co-expression network identifies novel genes controlling the seedto-seedling phase transition in Arabidopsis thaliana. Plant Physiol. 2016:170(4):2218-31.

100. Cordoba E, Aceves-Zamudio DL, Hernández-Bernal AF, RamosVega M, León P. Sugar regulation of SUGAR TRANSPORTER PROTEIN 1 (STP1) expression in Arabidopsis thaliana. J Exp Bot. 2015:66(1):147-59

101. Lam HM, Hsieh MH, Coruzzi G. Reciprocal regulation of distinct asparagine synthetase genes by light and metabolites in Arabidopsis thaliana. Plant J. 1998;16(3):345-53.

102. Cookson SJ, Yadav UP, Klie S, Morcuende R, Usadel B, et al. Temporal kinetics of the transcriptional response to carbon depletion and sucrose readdition in Arabidopsis seedlings. Plant Cell Environ. 2015:39(4):768-86.

103. Lee KW, Chen PW, Lu CA, Chen S, Ho THD, et al. Coordinated responses to oxygen and sugar deficiency allow rice seedlings to tolerate flooding. Sci Signal. 2009;2(91):ra61.

104. Lee KW, Chen PW, Yu SM. Metabolic adaptation to sugar $/ \mathrm{O}_{2}$ deficiency for anaerobic germination and seedling growth in rice. Plant Cell Environ. 2014;37(10):2234-44.

105. Bhalla PL, Singh MB. Agrobacterium-mediated transformation of Brassica napus and Brassica oleracea. Nat Protoc. 2008;3(2):181-9.

106. Cardoza V, Stewart CN. Increased Agrobacterium-mediated transformation and rooting efficiencies in canola (Brassica napus L.) from hypocotyl segment explants. Plant Cell Rep. 2003;21(6):599-604.

107. Jefferson RA, Kavanagh TA, Bevan MW. GUS fusions: beta-glucuronidase as a sensitive and versatile gene fusion marker in higher plants. EMBO J. 1987;6(13):3901-7.

108. Bradford MM. A rapid method for the quantitation of microgram quantities of protein utilizing the principle of proteindye binding Anal Biochem. 1976;72:248-54.

109. Wang XP, Li X, Li MM, Wen J, Yi B, Shen JX, Ma CZ, Fu TD, Tu JX. BnaA bZIP1 negatively regulates a novel small peptide gene, BnaC.SP6, involved in pollen activity. Front. Plant Sci. 2017;8:2117. 
110. Shenk JS, Westerhaus MO. Analysis of agriculture and food products by near infrared reflectance spectroscopy. Port Matilda: Infrasoft International; 1993. p. 36.
111. Gan L, Sun X. Establishment of math models of NIRS analysis for oil and protein contents in seed of Brassica napus. Scientia Agricultura Sinica. 2003;36(12):1609-13.
Ready to submit your research? Choose BMC and benefit from:

- fast, convenient online submission

- thorough peer review by experienced researchers in your field

- rapid publication on acceptance

- support for research data, including large and complex data types

- gold Open Access which fosters wider collaboration and increased citations

- maximum visibility for your research: over 100M website views per year

At BMC, research is always in progress.

Learn more biomedcentral.com/submissions 